\title{
Construction of Comprehensive Evaluation System of Material Dynamic Support Based on Multimodal Transport
}

\author{
Peng Ni \\ China Waterborne Transportation Research Institute, Beijing 100088, China \\ E-mail: nipeng@wti.ac.cn
}

Keywords: logistics enterprises, intelligent transportation system, multimodal transport, port logistics, information platform

\begin{abstract}
Integrated service logistics park is an important organization form of modern logistics enterprises. According to the economic factors of production (land, capital and labor) and the correlation between logistics and national economy, from the macro to the micro, from the two aspects of the total index and quality index, the comprehensive service logistics park economy is considered, conducive to the analysis of the current situation of the logistics industry, and the development of logistics industry is promoted, so that the government can effectively monitor the quality of development park. This paper has a guiding role in intelligent transportation system construction, port logistics information platform construction, container transport safety tracking system, electronic data interchange system, electronic port "single window" system construction, logistics standardization, multimodal transport and other fields.
\end{abstract}

\section{Introduction}

1 introduction of logistics demand and the impact of such as economy, policy, resources and other factors, the influence factors of the complex and changeable form, resulting in the logistics demand itself with the volatility and stochastic characteristics of the larger at the same time, highly nonlinear relationship between the factors of logistics demand and its influence, it is difficult to establish mathematics model, so how to accurately determine. The prediction has become a research hotspot in the field of [1], the current economic demand for logistics. The current logistics demand forecasting model is mainly divided into two categories: the traditional linear model and nonlinear model of modern, traditional models mainly include regression analysis method, time series method and so on, these methods assume that the logistics demand is a linear variation model for modern logistics system is complex and changeable, it is difficult to accurately reveal the variation trend, prediction accuracy low [2]. The main nonlinear model of hidden Markov model (Hidden Markov Models, HMM), artificial neural network (Artificial Neural Network, ANN), least squares support vector machine (Least Squares Support Vector Machine, LSSVM), the non linear model has good prediction ability, can better describe the nonlinear relation between logistics demand and its influencing factors the [3-5] has been applied widely in logistics demand forecasting.

\section{Construction of logistics information platform for two multimodal transport}

The logistics park is to achieve intensive logistics facilities and logistics operations together, or for the space of city logistics facilities layout rationalization and in other areas surrounding the city, focused on the construction of logistics facilities and logistics industry in many regions of the physical assembly; for freight services, production services, business services type and comprehensive service of four types, the main business scope and function of each type is: freight service location in a certain size or have one of the airport port or inland port, mainly to achieve different transport mode conversion.

Definition 1 (fuzzy set definition): $A=\left\{\left(x, \mu_{A}(x)\right) \mid x \in R\right\}$ fuzzy set can be defined as a set of ordered pairs, $\mu_{A}(A)$ in which a membership function called a fuzzy set. 
Definition 2 (normal fuzzy set): if the fuzzy set has at least one point and satisfies, then $x \in R$ the fuzzy set is called the normal fuzzy set $\mu_{A}(x)=1$.

Definition 3 (convex fuzzy set): if for arbitrary, and, $\lambda \in[0,1]$ satisfy the condition:

$$
\mu_{A}(\lambda x+(1-\lambda) y) \geq \min \left\{\mu_{A}(x), \mu_{A}(y)\right\}
$$

It is called the fuzzy set to be convex.

Definition 4 (fuzzy set composition): if the fuzzy number on a straight line satisfies the normal (definition 2) and convexity (definition 3), then it can form a fuzzy set.

$\gamma \in[0,1]$ is an important concept of fuzzy sets, assuming that any given fuzzy set defined on it is arbitrary, $\gamma$-cut $\left({ }^{\gamma} A\right)$ and strong $\gamma$-cut $\left({ }^{\gamma+} A\right)$ can be defined as:

$$
\left\{\begin{array}{c}
\gamma A=\{x \mid A(x) \geq \gamma\} \\
{ }^{\gamma+} A=\{x \mid A(x)>\gamma\}
\end{array}\right.
$$

We know that as the running time of the vehicle increases, ${ }^{t>t_{u}}$ the logistics supplier will reduce the job satisfaction and affect the quality of the work. It is assumed that when the working time, ${ }^{t<t_{l}}$ logistics providers member of the highest satisfaction activities of the work efficiency and the highest quality of service, when the working time, ${ }^{t<t_{l}}$ staff satisfaction with the logistics providers to decrease linearly with the increase of time, the work efficiency and service quality to a minimum. The following two hypotheses are proposed: (1) the distribution time is a normal variable with a specific mean and variance. (2) the satisfaction of the logistics supplier is a function of the distribution time, and it is linear in a certain time interval. The function curve as a logistics provider's satisfaction with time changes as shown in Figure 1.

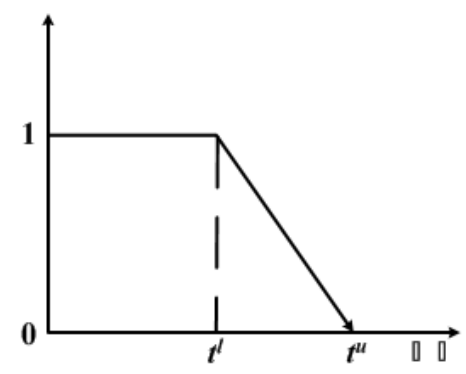

Figure 1 Logistics satisfaction time curve

Based on this, a stochastic distribution model can be constructed. If it is the longest travel time of the secondary degree of satisfaction, the normal distribution function can be expressed as:

$$
y=a_{1} x_{1}+a_{2} x_{2}+\cdots+a_{n} x_{n}
$$

The normal distribution function is satisfied, in which:

$$
\left\{\begin{array}{l}
\mu_{y}=a_{1} \mu_{1}+a_{2} \mu_{2}+\cdots+a_{n} \mu_{n} \\
\sigma_{y}^{2}=a_{1}^{2} \sigma_{1}^{2}+a_{2}^{2} \sigma_{2}^{2}+\cdots+a_{n}^{2} \sigma_{n}^{2}
\end{array}\right.
$$

If the distribution time of the vehicle from the node to the node is expressed, the normal distribution sequence is satisfied, $t_{i j}^{v} \sim \mathcal{N}\left(\mu_{i j}, \sigma_{i j}^{2}\right)$. For all distribution providers, the distribution time of their grade satisfaction is the same. In the ideal state, the total service time should satisfy the constraints.

$$
\sum_{i=1}^{n} t_{i}^{v} \sum_{j=1}^{n} x_{i j}^{v}+\sum_{i=1}^{n} \sum_{j=1}^{n} t_{i j}^{v} x_{i j}^{v} \leq t_{\alpha}
$$

$i \neq j, \quad v=1, \cdots, N V$, In the formula, the total number of vehicles for distribution is generally valued 
at 0 or 1 for the decision parameters.

The extension of public notice (4) can be obtained as follows:

$$
\begin{gathered}
t_{1}\left(x_{12}^{v}+\cdots+x_{1 N}^{v}\right)+\cdots+t_{N}\left(x_{N 1}^{v}+\cdots+x_{N N-1}^{v}\right) \\
+\left(t_{12}^{v} x_{12}^{v}+\cdots+t_{1 N}^{v} x_{1 N}^{v}\right)+\cdots+ \\
\left(t_{N 1}^{v} x_{N 1}^{v}+\cdots+t_{N N-1}^{v} x_{N N-1}^{v}\right) \leq t_{\alpha}
\end{gathered}
$$

Then, the percentage probability can be expressed as:

$$
p\left(\sum_{i=1}^{n} t_{i}^{v} \sum_{j=1}^{n} x_{i j}^{v}+\sum_{i=1}^{n} \sum_{j=1}^{n} t_{i j}^{v} x_{i j}^{v} \leq t_{\alpha}\right) \geq \alpha
$$

Then the distribution time of normal distribution can be expressed as:

$$
\left\{\begin{array}{l}
A=\sum_{i=1}^{n} \sum_{j=1}^{n} t_{i j}^{v} x_{i j}^{v} \sim \mathcal{N}\left(\mu_{A}, \sigma_{A}^{2}\right) \\
\mu_{A}=\sum_{i=1}^{n} \mu\left(t_{i}^{v}\right) \sum_{j=1}^{n} x_{i j}^{v}+\sum_{i=1}^{n} \sum_{j=1}^{n} \mu\left(t_{i j}^{v}\right) x_{i j}^{v} \\
\sigma_{A}^{2}=\sum_{i=1}^{n} \sigma^{2}\left(t_{i}^{v}\right) \sum_{j=1}^{n}\left(x_{i j}^{v}\right)^{2}+\sum_{i=1}^{n} \sum_{j=1}^{n} \sigma^{2}\left(t_{i j}^{v}\right) x_{i j}^{v}
\end{array}\right.
$$

It can be concluded that:

$$
p\left(A \leq t_{\alpha}\right) \Rightarrow p\left(\frac{A-\mu_{A}}{\sqrt{\sigma_{A}^{2}}} \leq \frac{t_{\alpha}-\mu_{A}}{\sqrt{\sigma_{A}^{2}}}\right) \geq \alpha
$$

The extended equation of the publicity (10) can be expressed as:

$$
\frac{t_{\alpha}^{v}-\left(\sum_{i=1}^{n} \mu\left(t_{i}^{v}\right) \sum_{j=1}^{n} x_{i j}^{v}+\sum_{i=1}^{n} \sum_{j=1}^{n}\left(t_{i j}^{v}\right) x_{i j}^{v}\right)}{\sqrt{\sum_{i=1}^{n} \sigma^{2}\left(t_{i}^{v}\right) \sum_{j=1}^{n}\left(x_{i j}^{v}\right)^{2}+\sum_{i=1}^{n} \sum_{j=1}^{n} \sigma^{2}\left(t_{i}^{v}\right)^{2} x_{i j}^{v}}} \geq Z_{\alpha}
$$

In this way, the VRPS problem can be extended to the optimization problem that takes into account the distribution time and time distribution.

\section{Comprehensive Evaluation System for Dynamic Support of Comprehensive Materials}

The logistics park has both the public welfare and the certain enterprise nature. From the perspective of the government, the role of the logistics park is to provide more support for the fundamental role in the development of the city and region, the regional economic development, optimize the investment environment, has a very good role in promoting regional competitiveness; and from the perspective of enterprises, they are concerned in the logistics Park is helpful to their business. Because of the dual identity of logistics park, there are many factors to consider in the economic operation evaluation of logistics park. The selection of indicators is a tedious and repeated improvement work. The advantages and disadvantages of a park is determined by the operators and the enterprises in the park. The social economic and environmental benefits brought by the park are finally reflected by the logistics enterprises. Because of the different development and construction modes and different policies in various regions, the integrated service type logistics park is difficult to determine the unified evaluation index. This combination of Hunan Changsha a comprehensive logistics park as an example, according to the economic factors of production (land, capital and labor) and the correlation between logistics and national economy, from the macro to the micro, from the two aspects of the total index, quality index to consider the comprehensive service logistics park economic operation state, the indicators and calculation methods can refer to the relevant national standards. 
Total volume index: from the point of view of industrial total, the demand for modern logistics market is increasing rapidly. Logistics industry is a complex or aggregated industry formed by the industrialization of logistics resources. As a converging point of service infrastructure and logistics enterprise, logistics infrastructure directly reflects the economic service capacity of the park.

(1) The total amount of social logistics goods: the total amount of social logistics referred to, refers to the total value of all goods that have been or are being delivered to the end user through the social logistics service during the first time in the reporting period. It is a manifestation of the value of the scale of the social logistics demand in the reporting period. The volume of the demand for the social logistics is reflected by the freight volume and the turnover of goods.

(2) Investment in fixed assets: fixed assets investment is the workload of building and purchasing fixed assets in the form of money. It is a comprehensive index reflecting the scale, speed, proportion and direction of investment in fixed assets. It is divided into four parts: basic construction, renewal and transformation, investment in real estate development and investment in other fixed assets.

(3) Freight volume: in the period of the reporting period, the quantity of goods that are actually completed by various means of transport are calculated by the units of weight (tons). Freight volume includes: railway freight volume, highway freight volume, water transport volume, civil aviation freight volume, pipeline transportation volume.

Turnover volume: in the reporting period, the enterprise uses all kinds of transportation tools to carry out the transport of goods on its own. Formula: freight turnover $=$ sigma (for each shipment of the cargo shipping weight distance $)=$ cargo freight distance *.

Main business income: refers to the income obtained by the enterprise through the logistics business activities during the reporting period.

The main business cost: refers to the reporting period, the logistics enterprises engaged in business activities by the actual business cost.

The introduction of a number of enterprises and the total assets of the reporting period: logistics enterprises owned or controlled by money value economic resources including all property claims and other rights. Assets are generally divided into mobile assets, long-term investment, fixed assets, intangible assets, deferred assets and other assets according to the nature of the flow. Measurement unit: ten thousand yuan.

The total number of employment: refers to the reporting period, including the total number of enterprises, the total number of employees in the park and the park operator staff.

The park covers a total area of 9: refers to the reporting period, the government planning for the use of land. Measurement unit: square meter.

2, quality indicators: these indicators reflect input output relationship, and the more output per unit input, the higher the efficiency of production factors and the quality of operation of the park economy, which is conducive to speed up the transformation of economic development from quantity to quality.

(4) Investment intensity: fixed assets investment per unit area within the scope of the project. Formula: = the intensity of investment projects with a total investment of fixed assets, the total land area of the project, the total investment in fixed assets projects including workshop, logistics infrastructure, equipment and price.

Logistics intensity: the logistics processing capacity per unit time and unit area. Formula: Logistics Park, logistics total intensity = annual total land area of the park.

(5) The rate of investment output. The calculation formula: the rate of investment output = total amount of logistics goods in the same year / the total investment in fixed assets of the year. This index reflects the quality of economic development from the perspective of investment efficiency of fixed assets, and is conducive to improving the scientific and technological level of investment in fixed assets and optimizing the structure of investment.

(6) The rate of land output: the increase in the output of land output per square meter in the Logistics Park reflects the comprehensive utilization of land.

Labor productivity: the per capita added value of the Logistics Park reflects the efficiency of the 
staff of the logistics park.

The evaluation index system of economic operation of the logistics park is a whole formed by various interrelated, interdependent and interrelated index, is the objective standards to measure the quality of economic development park, and provide the scientific basis for the feasibility study, project evaluation and decision-making, in favor of the government to supervise the quality of development park.

\section{Conclusion}

We must speed up the development of modern logistics, establish a modern logistics service system, and promote the development of other industries with logistics services. First, we should actively expand the demand for the logistics market, promote the interactive development of logistics enterprises and production and trade enterprises, and promote the socialization and specialization of logistics services. Two, we should accelerate the merger and reorganization of enterprises, and cultivate a large number of modern logistics enterprises with high service level and strong international competitiveness. Three we should promote the development of energy, mineral, automobile, agricultural products, medicine and other key fields, and accelerate the development of international logistics and bonded logistics. Four we should strengthen the construction of logistics infrastructure and improve the standardization of logistics and the level of information. The meeting identified nine key projects for the revitalization of the logistics industry, including multimodal transport and transport facilities, logistics parks, city and rural commodity distribution, logistics, manufacturing and logistics industry linkage development, logistics standards and technology promotion, public logistics information platform, logistics technology and emergency logistics etc. We believe that under the coordination of the central government and the local government, the adjustment and revitalization plan of the logistics industry can be effectively implemented, and the integrated service logistics park will also be further developed.

\section{Acknowledgement}

This work was in part supported by national key technology support program of Ministry of Science and Technology of China (2015BAG20B03).

\section{References}

[1] Du, X., Y. Zhu, Z. Peng, Y. Cui, Q. Zhang, Z. Shi, Y. Guan, X. Sha, T. Shen, Y. Yang, X. Li, Z. Wang, X. Li, and G. Liu. 2018. High concentrations of fatty acids and beta-hydroxybutyrate impair the growth hormone-mediated hepatic JAK2-STAT5 pathway in clinically ketotic cows. J Dairy Sci. 0302(18)30029-8

[2] Yingyue Zhang, Ammar Algburi, Ning Wang, Vladyslav Kholodovych, Drym O. Oh, Michael Chikindas, and Kathryn E. Uhrich, Self-assembled Cationic Amphiphiles as Antimicrobial Peptides Mimics: Role of Hydrophobicity, Linkage Type, and Assembly State, Nanomedicine: Nanotechnology, Biology and Medicine, 2017, 13(2), 343-352.

[3] Du X, Zhen S, Peng Z, Zhao C, Zhang Y, Zhe W, Li X, Liu G, Li X. 2017c. Acetoacetate induces hepatocytes apoptosis by the ROS-mediated MAPKs pathway in ketotic cows. Journal of Cellular Physiology 232: 3296-3308, 2017.

[4] Song Y, Li N, Gu J, Fu S, Peng Z, Zhao C, Zhang Y, Li X, Wang Z, Li X. 2016. $\beta$-Hydroxybutyrate induces bovine hepatocyte apoptosis via an ROS-p38 signaling pathway. Journal of Dairy Science 99(11):9184-9198.

[5] Arunkumar, N., Kumar, K.R., Venkataraman, V. Automatic detection of epileptic seizures using new entropy measures (2016) Journal of Medical Imaging and Health Informatics, 6 (3), pp. 724-730. 